\title{
Comunicação estratégica e inovação em micro e pequenas empresas (MPE) sob a ótica de Agentes Locais de Inovação (ALI)
}

\author{
STRATEGIC COMMUNICATION AND INNOVATION IN MICRO AND \\ SMALL-SIZED ENTERPRISES (SME) FROM THE PERSPECTIVE OF \\ LOCAL INNOVATION AGENTS (ALI)
}

\section{— Maria Eugênia Porém}

Pós-doutoranda em Comunicação pela Escola de Comunicações e Artes da Universidade de São Paulo (ECA-USP). Doutora em Educação e Mestre em Comunicação pela Universidade Estadual Paulista (Unesp). Professora assistente do Departamento de Comunicação Social da Faculdade de Arquitetura, Artes e Comunicação da Universidade Estadual Paulista (Faac/Unesp), campus de Bauru. Bolsista EXP, Nível SA (CNPq). Líder do grupo de pesquisa Núcleo de Comunicação, Inovação e Gestão.

E-mail: meporem@faac.unesp.br

Recebido em 12 de outubro de 2017. Aprovado em 5 de fevereiro de 2018.

\section{Resumo}

Este trabalho tem o objetivo de compreender a comunicação estratégica como indutora da inovação em micro e pequenas empresas (MPE). Para tanto, desenvolvem-se a pesquisa teórica, com base em levantamento bibliográfico, e a pesquisa aplicada, com fins exploratórios e aplicação de entrevista semiestruturada a 19 agentes locais de inovação, atuantes em MPE de Bauru e região. Adicionalmente foi aplicada a análise de conteúdo para interpretação dos resultados. Pôde-se concluir que as MPE não estabelecem relação entre a comunicação estratégica e a inovação. A comunicação é entendida como ferramenta para divulgação de produtos e serviços e a estratégia é utilizada de forma intuitiva.

Palavras-chave: Inovação. Comunicação estratégica. Micro e pequenas empresas. 


\section{Abstract}

This paper aims to understand strategic communication as an innovation driver in micro and small enterprises (MSEs). To do so, we developed both the theoretical research based on bibliographic survey and the applied research with exploratory purposes, which relied on a semi-structured survey with 19 local innovation agents that were active in MSEs from Bauru and its neighboring towns. Additionally, a content assessment was performed for interpreting the results. This study concluded that MSEs did not perceive any relations between strategic communication and innovation. Companies see communication as a tool for promoting products and services and they apply the strategy intuitively.

Keywords: Innovation. Strategic communication. Micro and small enterprises.

\section{Introdução}

A inovação, palavra de caráter polissêmica que abriga múltiplas acepções, é um dos diferenciais que mais tem sido valorizado no século 21 . Sob o ponto de vista econômico, esse fenômeno é fortemente associado às mudanças necessárias ao desenvolvimento de um país, além de ser um grande indutor da performance competitiva das organizações. Não por acaso, Schumpeter (1982), nos anos 1930, já considerava a inovação como motor do capitalismo e força propulsora de mudanças mundiais.

Nas organizações, a inovação está atrelada ao processo de utilização de informações para criar significados, construir conhecimentos e tomar decisões que resultem em transformações e vantagens competitivas nos negócios (CHOO, 2006).

A inovação também está diretamente relacionada às mudanças organizacionais $\mathrm{e}$ aos agentes que se envolvem nesse processo por meio da comunicação. Queremos dizer que a inovação se constitui a partir dos comportamentos coletivos e individuais que são intercambiados e negociados nas rotinas organizacionais, e que estão condicionados pelas culturas que tecem e ressignificam o cotidiano das organizações.

Por esse ângulo, pode-se considerar que a inovação está intrinsecamente relacionada às culturas que constituem uma organização e que interferem na forma de agir e pensar, nos hábitos, nos valores, nas visões de mundo e no modelo mental daqueles que estão envolvidos com os seus processos - ou seja, ela se refere à cultura organizacional. Não por acaso, a cultura organizacional pode ou não ser um elemento facilitador da inovação, pois "a cultura cria os parâmetros para qual comportamento é desejável e será encorajado e qual comportamento é inaceitável e será censurado" (McLean, 2005, p. 241). Para McLean (2005), o encorajamento organizacional e de grupos de trabalho, 
conjuntamente ao oferecimento de maior liberdade e autonomia para os agentes organizacionais são fatores da cultura organizacional que podem facilitar a inovação. Por outro lado, o controle organizacional excessivo é considerado pelo autor como um fator impeditivo à capacidade de inovar.

Nessa mesma linha, Kaasa e Vadi (2010, p. 584) reforçam que a "cultura afeta a inovação porque molda os padrões de lidar com a novidade, iniciativas individuais e ações coletivas e entendimentos e comportamentos em termos de riscos, assim como de oportunidades".

O entendimento sobre a relação entre inovação e cultura organizacional considera os aspectos da organização enquanto complexidade culturalmente construída, edificada pelo intercâmbio das culturas de seus agentes com a da empresa e de suas interações. Adicionalmente, a cultura da empresa e de seus agentes é também afetada pelo contexto sociocultural vivido.

Para Ahmed (1998) a cultura é a base da inovação, constituindo-se como um dos fatores que facilitam e podem impulsionar ações nesse sentido. Considerando esse ponto de vista, para se tornar inovadora uma organização necessita desenvolver a cultura de inovação, uma vez que, segundo Ahmed (1998), inovar é a força motriz da transformação e a cultura é seu principal determinante.

Sabendo disso, como uma organização poderá desenvolver uma cultura de inovação?

Segundo Zien e Buckler (1997, p. 276) isso será possível quando a organização se envolver na edificação do "espírito inovativo vibrante e robusto empregando princípios de inovação", o que é possibilitado pelo incentivo ao intercâmbio de ideias, mudanças, criatividade e contradições que afloram na interação entre os agentes organizacionais. Esse processo é facilitado por meio da criação de um ambiente de aprendizado (locus) para o conhecimento, instituído pela comunicação direcionada estrategicamente para esse objetivo.

Ao relacionarmos cultura de inovação à comunicação, apoiamo-nos em perspectivas conceituais oferecidas por Johannessen e Olsen (2011 apud BRUNO-FARIA; FONSECA, 2014) e por Das (2003 apud BRUNO-FARIA; FONSECA, 2014).

Johannessen e Olsen (2011 apud BRUNO-FARIA; FONSECA, 2014, p. 380) consideram a comunicação como uma facilitadora da inovação. Os mesmos autores

consideram essencial que se transformem processos de comunicação em capacidades de comunicação. Para isso, deve envolver criação de valor e ser orientada para desenvolvimento, transferência e integração do conhecimento. A cultura de inovação necessita de mecanismos de coordenação e interação que abranjam trocas de informações e conhecimentos que contribuam para o desenvolvimento do conhecimento - que é a base para a inovação. As capacidades de comunicação constituem um sistema que preserva a criação de valor e combina comunicação econômica/técnica; gestão da comunicação; e comunicação social e cultural. (Ibid., p. 380). 
Já para Das (2003 apud BRUNO-FARIA; FONSECA, 2014, p. 380) “quando a comunicação associa-se ao compartilhamento de uma cultura, os empregados tendem a ser mais unidos em suas ações, o que interfere em seu desempenho".

Ressalta-se o valor da comunicação como estratégia para o desenvolvimento de uma postura inovativa, na medida em que a inovação deverá ser incorporada pela cultura organizacional como norma básica, de modo que os comportamentos de seus agentes e os valores compartilhados facilitem esse processo.

Esta pesquisa, portanto, tem como objetivo central compreender a comunicação estratégica como indutora da cultura da inovação no âmbito das organizações contemporâneas, mais especificamente, das micro e pequenas empresas (MPE). Para tanto, procurou-se investigar o modelo de gestão, a inovação ou cultura de inovação adotada e a comunicação estratégica das MPE sob a perspectiva de 19 Agentes Locais de Inovação do Sebrae Bauru.

Um dos motivos pelos quais escolhemos pesquisar as micro e pequenas empresas diz respeito à sua grande representatividade na economia nacional. Elas correspondem a $99 \%$ do total de empresas privadas não agrícolas no país (SMPE, 2014), a 52\% dos empregos formais e a $40 \%$ da massa salarial. Porém, a despeito desses dados, as MPE apresentam contradições que as impedem de se tornarem sustentáveis. Por exemplo, elas possuem escassez de recursos e têm dificuldade em se manter competitivas em relação às médias e grandes empresas - prova disso é o elevado índice de mortalidade. Segundo o Sebrae (2008), 64\% das micro e pequenas empresas fecham suas portas antes de completarem seis anos de atividade.

De acordo com Marchesnay (2003, p. 107 apud VERAS; SILVA; PORÉM, 2017, p. 4), “de 95 a 98\% das empresas registradas na maioria dos países são micro e pequenas empresas". Entretanto, na contramão dessa representatividade, devemos ressaltar que "a valorização das grandes organizações, que costumam ser vistas como sinônimo de máxima eficiência, acaba por ocultar muitas vezes o protagonismo das micro e pequenas empresas, fazendo com que esses negócios se tornem 'ilustres desconhecidos"” (MARCHESNAY, 2003, p. 110 apud VERAS; SILVA; PORÉM, 2017, p. 5).

\section{Inovação e micro e pequenas empresas: desafios para a comunicação}

Segundo Schumpeter (1982), as grandes corporações são mais propensas a inovar do que as micro e pequenas empresas. Neves (2002) aponta que isso se deve a alguns fatores, tais como acesso facilitado às linhas de financiamento, economia de escala nas atividades de pesquisa e desenvolvimento, maior poder político e maiores chances de elaborar e implementar o que se tornará o design dominante de um determinado setor. Além disso, histórica 
e culturalmente, as MPE possuem posturas mais conservadoras em relação a mudanças. Certamente isso está ligado ao fato de que mudanças e melhorias normalmente implicam investimentos e riscos, de modo que empresas com estruturas organizacionais enxutas e capital de giro mais restrito costumam resistir à ideia de mudar, bem como à necessidade de inovar.

Jucevicius (2010) argumenta que as mudanças só são possíveis quando existem valores estáveis ligados à inovação e padrões de cooperação que direcionem as atividades dos indivíduos na organização e nas relações externas. Para que esses padrões reúnam todos em torno de objetivos comuns e potencializem o desempenho inovativo, a comunicação precisa associar-se estrategicamente ao compartilhamento da cultura de inovação.

Dessa forma, reconhecemos a centralidade da comunicação nos processos de mudança das MPE, tão necessários à inovação, na medida em que os agentes organizacionais envolvidos precisam transformar seu modelo mental, rompendo com paradigmas comportamentais impeditivos à inovação e criando uma forma de gestão que permita a transformação cultural dessas empresas. Afinal, seu modelo de gestão, normalmente mediado por barreiras culturais e comportamentais, apresenta características impeditivas à inovação, quais sejam: (1) organizacionais: pobreza de recursos; gestão centralizadora; situação extraorganizacional incontrolável; fraca maturidade organizacional; fragilidade no mercado; estrutura simples e leve; ausência de planejamento; pouca especialização; estratégia intuitiva; sistema de informações simples; (2) decisionais: tomada de decisão intuitiva; horizonte temporal de curto prazo; inexistência de dados quantitativos; alto grau de autonomia decisória por parte do dono; racionalidade econômica, política e familiar; (3) individuais: onipotência do proprietário/dirigente; identidade entre pessoa física e jurídica; dependência de certos funcionários; influência pessoal do proprietário/dirigente; simbiose entre patrimônio social e pessoal; posse dos capitais; propensão a riscos (LEONE, 1999).

Sabendo que a inovação deve estar ligada a uma perspectiva de transformação cultural que a antecede, alguns dos aspectos impeditivos apontados por Leone (1999) precisam ser superados para garantir a mudança. Isso porque as MPE necessitam de vetores culturais que modifiquem significativamente o modo de pensar e de agir de seus agentes, bem como o modelo mental que se tem sobre a inovação - ela deve passar a ser entendida como meio, e não como fim.

Corroborando com essa assertiva, Messina (2001, p. 226-227) argumenta que:

a inovação é algo aberto, capaz de adotar múltiplas formas e significados, associados com o contexto no qual se insere. Destaca-se, igualmente, que a inovação não é um fim em si mesma, mas um meio [...]. A inovação foi definida como processo multidimensional, capaz de 
transformar o espaço no qual habita e de transformar-se a si própria. Nesse sentido, diversos autores referem que inovar consiste, antes de mais nada, em uma disposição permanente em direção à inovação ou de inovar a inovação.

Nesse aspecto, ressalta-se o valor da comunicação como estratégia para o desenvolvimento de uma cultura inovativa, uma vez que a inovação deverá ser incorporada pela cultura organizacional como norma básica e em que os comportamentos dos agentes organizacionais e os valores compartilhados facilitem esse processo.

Parte-se do entendimento de que:

A comunicação sempre desempenhou papel central na inovação. Contudo, o aumento da complexidade das relações internas e externas das organizações, e dos indivíduos entre si, combinado à crescente demanda competitiva por inovação, lança desafios inéditos sobre a forma de pensar e atuar na comunicação organizacional. (CAJAZEIRA; CARDOSO, 2010, p. 269).

Diante do exposto, entendemos a comunicação como indutora da cultura de inovação, uma vez que "ela é o oxigênio que confere vida às organizações. Está presente em todos os setores, em todas as relações, em todos os fluxos de informação, espaços de interação e diálogo" (DUARTE; MONTEIRO, 2009, p. 334).

Não obstante, Duarte e Monteiro (2009) chamam atenção para uma questão importante: apesar da relevância da comunicação na geração de valor inovativo dentro de uma organização, vivencia-se um paradoxo ao não conseguir transformar essa força motriz em energia vital. Em outras palavras, existem barreiras organizacionais e culturais que impedem que a comunicação se transforme em competência estratégica de uma empresa.

Esse quadro interfere na constituição de uma cultura da inovação, posto que "da comunicação emergem as culturas em uma organização. A comunicação cria e recria realidades" (MARCHIORI, 2008, p. 192). Dito de outro modo, a comunicação é definida pela interação de pessoas nas e entre organizações, sendo um processo constitutivo da realidade organizacional (CALDAS, 2010).

No contexto das micro e pequenas empresas, comunicação e inovação apresentam traços bastante particularizados. Essas empresas normalmente possuem uma contradição latente à sua própria natureza: apesar de serem um dos sustentáculos da economia, dispõem de condições limitadas de crescimento e desenvolvimento que podem dificultar a sua perenidade e a implementação de boas práticas de inovação. Além disso, estão inseridas em um cenário complexo e mutável. É nesse contexto da era digital que as MPE 
contemporâneas operam e a situação dessas organizações se particulariza nos desafios que enfrentam - seus ajustes, obstáculos, adaptações e superações.

Portanto, evidenciamos a necessidade da obtenção de competências comunicacionais estratégicas que possam proporcionar o desenvolvimento inovativo nas MPE e possibilitar uma resposta adequada às demandas geradas pela era digital.

\section{Comunicação estratégica: competência essencial à inovação}

A comunicação sob a perspectiva estratégica possui bases conceituais ainda em construção, na medida em que nos referimos a um campo cujas dúvidas na definição de seu objeto de estudo e de seu enfoque teórico-metodológico refletem ao mesmo tempo a complexidade do fenômeno comunicacional e a constituição de um panorama importante de pesquisa, sobretudo no que se refere ao âmbito das organizações.

Persiste, por exemplo, a dificuldade em se formar um conceito aglutinador que dê conta da complexidade dos fenômenos organizacionais ligados à comunicação estratégica. Sobretudo porque comunicação estratégica não significa a simples somatória de dois conceitos isolados, que unidos se tornam autoexplicativos. Ao contrário disso, a comunicação estratégica deve ser encarada como um projeto transformador que se constrói em conjunto, de forma cooperativa e participativa (MASSONI, 2013). Sobre isso Oliveira e Paula (2014, p. 3) argumentam:

Percebemos com certa frequência o uso da expressão comunicação estratégica de uma forma vaga, sem explicitação do seu conceito, muitas vezes tendendo ao senso comum. Quando falamos de estratégias de comunicação, propomos ir além da ideia de qualificar a comunicação - como estratégica ou não -, mas sim evidenciar a força das interações e das relações estabelecidas nos processos comunicativos no contexto organizacional.

É a partir dessa perspectiva que compreendemos a comunicação estratégica, reconhecendo-a como competência inexoralmente ligada à cultura de inovação em organizações.

Não obstante, percebe-se o uso indiscriminado e pouco consciente da palavra comunicação, muitas vezes associada a outras rotinas organizacionais cujos impactos estão ligados à venda - a exemplo do marketing. Da mesma forma, a comunicação organizacional está muito vinculada à prática instrumental e pouco reflexiva, exclusivamente preocupada com os efeitos que poderá causar nos resultados financeiros de uma empresa. Isso coloca a comunicação muito mais como atividade acessória às rotinas de trabalho e 
apoio aos negócios do que como lugar de encontro entre atores sociais que mantêm uma negociação de significados na construção do desenho estratégico.

A pouca reflexão e consciência sobre o protagonismo da comunicação estratégica no âmbito organizacional pode estar relacionada à tradição da administração moderna de caráter cartesiano e instrumental -, ainda bastante presente no universo empresarial. Essa postura reduz tanto a comunicação quanto a estratégia a ferramentas operacionais que têm como objetivo maximizar os lucros, o que tende a desassociar sua unicidade conceitual. Sob o paradigma burocrático, essa tradição foi inspirada nos princípios militares da "máquina de guerra prussiana" (CUNHA, 2011). Baseados na ordem e na racionalização, os objetivos dentro dessa perspectiva se fortaleciam nos parâmetros instituídos por uma prática organizacional disciplinar, controladora e pautada na subordinação. A racionalidade técnica, o foco no aspecto funcional das atividades, a precisão mecânica desejada nas operações diárias, a hierarquização e o ordenamento das relações de trabalho são alguns dos aspectos característicos dos modelos de gestão difundidos desde o século 19 - reforçados e aperfeiçoados no século 20 e ainda muito presentes no século 21 -, herdados das teorias clássicas da administração.

Não por acaso, a primeira teoria sobre estratégia tem seus aportes fundamentados na prática militar e na economia acadêmica. Segundo Whittington (2002, p. 15-16) “desde então, as ideias econômicas sobre otimização racional e as expectativas militaristas sobre comando hierárquico continuaram a ressoar no pensamento clássico sobre formulação e implementação estratégica".

Dessa mesma forma ocorreu com os estudos sobre comunicação no contexto organizacional. Até os anos 1980 os aportes conceituais sobre comunicação organizacional desdobraram-se, principalmente, em duas abordagens de orientação modernista: "(1) as habilidades que tornam os indivíduos mais eficientes na comunicação, em seu trabalho, e (2) os fatores que caracterizam a eficiência da comunicação no sistema inteiro" (REDDING; TOMPKINS, 1988 apud PUTNAN; PHILLIPS; CHAPMAN, 2012, p. 79).

Por esse motivo os estudos sobre a comunicação no âmbito das organizações visavam à maximização do lucro e, para isso, utilizavam-se instrumentos administrativos e gerenciais que pudessem potencializar a produtividade - normalmente a propaganda e a promoção de vendas. Logo, "na tradição modernista, as organizações eram entidades racionais e instrumentais; assim, a comunicação incorporava um viés utilitarista ou instrumental" (PUTNAN; PHILLIPS; CHAPMAN, 2012, p. 79), pois as ações de comunicação deveriam gerar resultados tangíveis para essas organizações. Daí o uso quase exclusivo da persuasão e da propaganda como formas mais apropriadas para "vender" produtos e serviços. 
A visão reducionista sobre o potencial da comunicação, o forte apelo funcional e transmissivo, o estudo da mensagem e, posteriormente, de seus efeitos sobre as pessoas constituíam a principal base dos estudos da comunicação até a década de 1980. Podemos dizer, então, que a comunicação e a estratégia se consolidaram como conceitos dissociativos, em uma relação em que a comunicação servia tecnicamente à estratégia.

Tradicionalmente, pode-se dizer que, sob uma perspectiva modernista, a relação comunicação-estratégia tem sido vista, sobretudo, como uma relação de subordinação daquela a esta: a comunicação é percebida como algo que vem à cena apenas após a tomada de decisões estratégicas e a sistematização dessas decisões em um plano de ação. Seu papel no processo estratégico é visto como de natureza técnica e sua função é essencialmente instrumental midiática: produzir informação, sensibilizar (emocionalmente), estimular e provocar mobilização, garantindo com isso o conhecimento e adesão daqueles potencialmente envolvidos na implementação de estratégias. (REIS; MARCHIORI; CASALI, 2010, p. 174).

A partir da década de 1980, a relação comunicação-estratégia, até então de natureza exclusivamente racional e técnica, abriu-se a novas perspectivas que levavam em conta a trama de significados que configuram a organização contemporânea. Talvez por conta das tecnologias da informação e da comunicação (TIC) e das mudanças por elas influenciadas, que fizeram emergir vulnerabilidades e ambiguidades e impactaram diretamente o ambiente organizacional. Não por acaso, esse cenário passa a desafiar "la funcionalidade de las herramientas de gestión con que las organizaciones abordan su actividad cotidiana" (MANUCCI, 2008, p. 7).

Somados a isso, os desafios lançados às organizações à luz desse contexto estão redefinindo sua atuação e conduta. Os cenários movediços e fluidos atuais impõem competências comunicacionais estratégicas que sejam capazes de superar a visão unívoca de realidade organizacional.

Por isso a pesquisa em questão parte do pressuposto de que a formação repertorial e comportamental gerada pela comunicação estratégica no cotidiano das organizações poderá refletir no processo de inovação.

\section{Caracterização e aplicação da pesquisa}

O estudo tem como objetivo compreender a comunicação estratégica como indutora da cultura de inovação em micro e pequenas empresas (MPE) sob a ótica de especialistas ligados ao campo profissional da inovação. Para tanto, desenvolveu-se pesquisa teórica e aplicada. A pesquisa teórica se baseou no levantamento bibliográfico, 
com destaque para as obras de Jucevicius (2010), Leone (1999), Cajazeira e Cardoso (2010), Duarte e Monteiro (2009), Massoni (2013) e Manucci (2008). A pesquisa aplicada, com fins exploratórios, pautou-se na realização de entrevista semiestruturada com 19 especialistas ${ }^{1}$ em inovação atuantes em micro e pequenas empresas que participam do Programa Agentes Locais de Inovação (ALI), desenvolvido em parceria entre o Serviço de Apoio às Micro e Pequenas Empresas (SEBRAE) e o Conselho Nacional de Desenvolvimento Científico e Tecnológico (CNPq, 2015). A amostra se constitui como não probabilística e por conveniência.

Optou-se pelo emprego da técnica de entrevistas e a interpretação dos resultados foi feita por meio da análise de conteúdo (AC). Convém ponderar que na $\mathrm{AC}$ "o analista, tendo à sua disposição resultados significativos e fiéis, pode, então, propor inferências e adiantar interpretações a propósito dos objetos previstos -, ou que digam respeito a outras descobertas inesperadas" (BARDIN, 2009, p. 127).

Após a coleta de dados realizada no mês de agosto de 2017, passou-se à transcrição das entrevistas - fase de exploração do material coletado - e, por meio de uma leitura preliminar, foram definidas 3 categorias de análise: Modelo de gestão; Inovação/cultura de inovação e Comunicação estratégica. Para a interpretação de cada categoria, buscou-se o agrupamento dos pontos em comum, visando muito mais ao caráter exploratório e descritivo da pesquisa. Devemos lembrar que os resultados e discussões se baseiam no entendimento da amostra estudada, ou seja, partem do ponto de vista dos Agentes Locais de Inovação (ALI) sobre as MPE atendidas por eles.

\section{Resultados e discussões}

Os resultados serão apresentados por meio do agrupamento das expressões comuns aos 19 respondentes, alocadas em categorias de análise. Restringimo-nos a apresentar apenas alguns excertos das falas dos participantes devido ao limite de páginas do artigo. No entanto, a discussão será feita relacionando as reflexões obtidas no levantamento bibliográfico e os resultados da pesquisa aplicada.

\section{Modelo de gestão}

De acordo com as respostas é possível caracterizar o modelo de gestão das MPE a partir do agrupamento das expressões comuns destacadas pelos respondentes (Quadro 1), quais sejam:

1 Para manter o anonimato, os respondentes serão assim caracterizados na pesquisa: R1, R2, R3 etc. 
Quadro 1. Itens comuns atribuídos pelos respondentes ao modelo de gestão das MPE atendidas pelos ALI

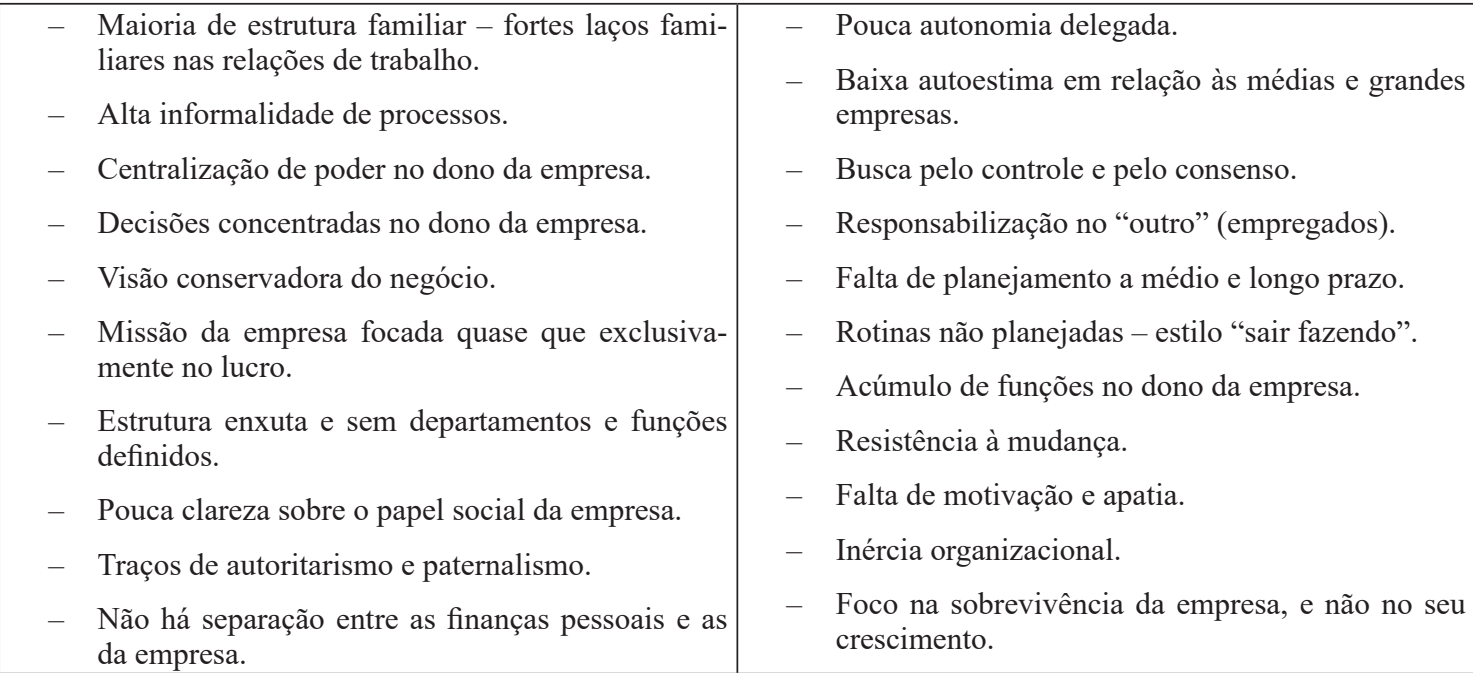

Fonte: Elaborado pela autora

O modelo de gestão caracteriza a maneira como uma empresa conduz suas atividades e formata sua estrutura. Também constitui e é constituído pela cultura organizacional e influencia a maneira de pensar e agir dos agentes organizacionais. Segundo Crozatti (1998) "o modelo de gestão é produto do subsistema institucional, que representa as principais determinações, vontades e expectativas do proprietário ou principal gestor, de como as coisas devem acontecer na empresa". Logo, comunicação estratégica e inovação estão diretamente relacionadas ao modelo de gestão de uma organização e ao entendimento que o gestor principal da empresa tem sobre elas. Podemos perceber que os itens elencados como principais características das MPE, sob o ponto de vista dos respondentes (Quadro 1), criam barreiras tanto à comunicação estratégica quanto à inovação. É importante destacar também que o modelo mental do dono da empresa, que faz parte do modelo de gestão, é um dos fatores mais impeditivos nesse aspecto. Como exemplo, o respondente R2, quando questionado a respeito dos obstáculos à inovação, disse:

R2: A maior parte dos empresários faz toda a parte da gestão: financeira, de marketing, de pessoas, de processos. Então é o tempo todo voltado para esse dia a dia engessado. Então, eles perdem muito tempo em processos muito bagunçados que poderiam ser otimizados e não conseguem ver além daquilo. Não conseguem pensar além daquilo, então o tempo que eles gastam tentando fazer esses processos, eles perdem na hora de fazer inovação. De pensar diferente, de tentar diferente, porque quando você começa uma ação de inovação ela requer tempo, planejamento para execução, para análise de dados, então isso é uma barreira também grande. 
Ainda sobre o modelo mental dos empresários quanto à inovação e à comunicação, o respondente R1 explanou:

R1: Acho que tem o sentimento de "eu sou pequeno e inovar não é para mim, o que eu faço não é inovação”. Eles fazem milhões de coisas que são inovações, mas eles não têm a concepção de que o que eles fazem é inovação. São inovações. Então, ficava esse distanciamento. Ou inovar é caro, ou a minha empresa não tem condições. Eles não conseguiam pensar que eles poderiam ter inovações sem custo nenhum e que poderia trazer resultado também. Para eles, a inovação estava relacionada a investimento e à questão de: eu sou pequeno, e isso é para empresa maior.

Diante do exposto, evidenciamos que a figura do dono da MPE é muito representativa nas relações que se estabelecem interna e externamente à organização. Se este se mantém resistente às mudanças e tem no conservadorismo um forte traço de atuação, sua motivação para inovar pode estar comprometida. Da mesma forma, como é possível pensar em comunicação estratégica voltada para fluidez, cooperação e colaboração - essenciais para a inovação - se o proprietário se coloca de forma autoritária e, ao mesmo tempo, paternalista com seus empregados?

\section{Inovação/cultura de inovação}

Para os respondentes, as MPE atendidas associam inovação quase que exclusivamente a tecnologia. Essa é uma relação muito presente no imaginário das empresas de forma geral. A importância da inovação tecnológica é amplamente difundida pela mídia e pelos governos, reforçando que a aquisição de tecnologia é o principal fator para a inovação. Embora seja consenso a importância da inovação tecnológica para as MPE, ela não deve ser entendida como única forma de inovação. Foi possível notar nas respostas dos 19 entrevistados que isso prejudica o desenvolvimento de boas práticas de inovação nas MPE porque seus gestores relacionam inovação a altos custos. Trata-se de um modelo mental arraigado e que impede os gestores das MPE relacionarem inovação a pequenas mudanças, por exemplo. Um excerto extraído da fala de um dos respondentes atesta tal afirmação: "R3: Inovação [...], a partir daquilo que os empresários pensam: tecnologia, grandes investimentos, não seria simplesmente uma mudança nunca antes realizada".

A inovação normalmente não é encarada como um processo. O entendimento a seu respeito está vinculado à capacidade de vender produtos e serviços e de elevar o faturamento da empresa. Ou seja, ela está invariavelmente ligada às possibilidades de aumento dos resultados financeiros, sendo, portanto, um fim em si mesma. 
Nessa mesma linha, a cultura de inovação, na visão dos respondentes, está relacionada a tecnologia, alto custo e aumento de resultados financeiros, ou seja: a atividades que têm a inovação como fim, e não como meio. Como, então, romper com esse modelo mental de valores, atitudes e práticas que tornam quase impossível criar uma cultura de inovação nas MPE?

Embora não tenhamos respostas prontas para essa questão, podemos afirmar que inovação diz respeito a uma perspectiva de transformação cultural e, dessa maneira, a comunicação estratégica é essencial para a modificação do modelo mental vigente um modelo cultural que também é incorporado por meio da comunicação. Queremos dizer que as mudanças só são possíveis quando existe o compartilhamento de valores estáveis ligados à inovação e a padrões de cooperação que direcionem as atividades dos indivíduos na organização e em suas relações externas, como defende Jucevicius (2010). Esses valores culturais, vetores para a criação de uma cultura de inovação, são instituídos por meio da comunicação estrategicamente pensada para promover o compartilhamento de conhecimentos, ideias, aprendizados e experiências. Dessa maneira, a comunicação estratégica direcionada para a criação de um ambiente facilitador de opiniões, expressão de dúvidas, contradições e questionamentos é essencial para a constituição de uma cultura inovativa.

\section{Comunicação estratégica}

Destacamos que, segundo os respondentes, as MPE entendem a comunicação de forma exclusivamente instrumental, cuja função está voltada, sobretudo, a resultados financeiros. Para os entrevistados, os micro e pequenos empresários não conseguem vislumbrar a ligação da comunicação com a estratégia para gerar uma cultura de inovação. A comunicação está relacionada aos canais e aos meios pelos quais os gestores podem divulgar seus produtos e serviços. Internamente, a ausência de diálogo gera falta de cooperação e colaboração nessas empresas. Não há espaços dialógicos para o compartilhamento de conhecimentos, ideias, opiniões e experiências. Os gestores buscam muito por harmonia, pois são avessos a contradições, acasos e questionamentos. Primam pelo consenso a qualquer custo. A proximidade, própria das MPE, não facilita a comunicação e em alguns casos chega, inclusive, a atrapalhar, pois não há separação de vida pessoal e profissional no relacionamento entre empresário e empregados. A estratégia é feita de forma intuitiva e amadora e associa-se muito mais a técnicas de comunicação - eventos e publicações em mídias sociais, por exemplo. Da mesma forma, a comunicação é vista como algo natural e, de tão natural, não necessita de gerenciamento e planejamento - ela simplesmente acontece. Para exemplificar tal inferência destacamos o excerto a seguir: 
R4: estratégia é fazer uma promoção de vendas, estratégia é fazer um coquetel e chamar mais clientes, estratégia é mandar sacola ${ }^{2}$ para o cliente. Isso para ele é a estratégia. São ações muito pontuais com resultados em curto prazo, não é nada pensando assim: "nossa daqui 5 anos eu quero estar em tal lugar".

Assim, a ideia do micro e pequeno empresário é falar do produto, porque meu produto é o melhor, porque eu tenho o melhor atendimento, e porque eu faço a coisa melhor do mundo. Não tem muito a visão do próprio cliente: "Que beneficio eu estou oferecendo", "o que o cliente tem a ganhar com o meu produto".

Finalmente, podemos inferir que a comunicação estratégica é inexistente nas MPE sob o ponto de vista dos ALI entrevistados. Para eles as MPE não têm consciência da importância da comunicação estratégica e de sua centralidade no processo de criação de uma cultura de inovação. Podemos atribuir tais perspectivas evidenciadas na pesquisa aos modelos tradicional e modernista de estratégia e comunicação, alicerçados no funcionalismo e no instrumentalismo herdados das teorias clássicas da administração.

\section{Considerações finais}

A pesquisa consistiu em compreender se a comunicação estratégica pode ser considerada indutora da cultura de inovação em micro e pequenas empresas (MPE) sob a ótica de especialistas ligados ao campo profissional da inovação. De acordo a literatura consultada, fica evidente a relação inexorável entre comunicação estratégica e cultura de inovação. Da mesma forma, demonstramos que as MPE referenciadas pelos respondentes não conseguem transformar a comunicação em energia vital para a empresa e, tampouco, para a cultura de inovação. As barreiras organizacionais e culturais ligadas aos modelos mental e de gestão dos donos das MPE impedem que a comunicação se torne uma competência estratégica para a inovação.

Não obstante, a pesquisa trouxe também alguns apontamentos importantes: como esses especialistas atenderam as MPE pelo programa ALI durante mais de dois anos, a maioria relatou que no início do atendimento existiam muitas barreiras à inovação nas falas dos donos dessas organizações. Com o passar do tempo, muito diálogo, compartilhamento de opiniões, conhecimentos e experiências, muitos deles foram ressignificando a ideia de inovação como algo inacessível e, atualmente, já conseguem,

2 O respondente se refere às MPE do ramo de varejo de vestuário que enviam sacolas de roupas para a casa dos seus clientes para que esses tenham mais comodidade e conveniência para comprar. 
mesmo que de maneira tímida, reconhecer a sua importância e implementar algumas ações inovativas. Essa observação, feita pela maioria dos especialistas participantes da pesquisa, sinaliza e fortalece que a comunicação é essencialmente transformadora, pois a estratégia de comunicação utilizada pelos especialistas - entendida aqui como diálogo e compartilhamento - e desenvolvida ao longo desses dois anos foi, sem dúvida, uma competência essencial para a mudança de conduta e a ressignificação da inovação de grande parte das MPE referenciadas neste estudo.

\section{Referências}

AHMED, P. K. Culture and climate for innovation. European Journal of Innovation Management, [S.1.], v. 1, n. 1, p. 30-43, 1998.

BARDIN, L. Análise de conteúdo. 4. ed. Lisboa: Edições 70, 2009.

BRASIL. Secretaria da Micro e Pequena Empresa. Tratamento diferenciado às micro e pequenas empresas: legislação para estados e municípios. Brasília, DF: SMPE, 2014. Disponível em: $<$ https://goo.gl/RzXMPM>. Acesso em: 19 fev. 2018.

BRUNO-FARIA, M. F.; FONSECA, M. V. A. Cultura de inovação: conceitos e modelos teóricos. RAC, Rio de Janeiro, v. 18, n. 4, p. 372-396, jul./ago. 2014. Disponível em: <https://goo.gl/uipG24>. Acesso em: 19 fev. 2018.

CAJAZEIRA, J. E. R.; CARDOSO, C. Comunicação e inovação: correlações e dependências. In: MACHIORI, M. (Org.). Comunicação e organização: reflexões, processos e práticas. São Caetano do Sul: Difusão, 2010. p. 269-285.

CALDAS, M. P. O nexo comunicação-organização: um prelúdio às múltiplas avenidas de cooperação e de mútuo aprendizado entre comunicação organizacional e estudos organizacionais. In: MACHIORI, M. (Org.). Comunicação e organização: reflexões, processos e práticas. São Caetano do Sul: Difusão, 2010. p. 29-46.

CHOO, C. W. A organização do conhecimento: como as organizações usam a informação para criar significado, construir conhecimento e tomar decisões. São Paulo: Senac, 2006.

CONSELHO NACIONAL DE DESENVOLVIMENTO CIENTÍFICO E TECNOLÓGICO. ALI Agentes Locais de Inovação. CNPq, [S.1], 18 jan. 2015. Disponível em: <https://goo.gl/cFzGh6>. Acesso em: 19 fev. 2018.

CROZATTI, J. Modelo de gestão e cultura organizacional: conceitos e interações. Caderno de Estudos, São Paulo, n. 18, maio-ago. 1998. Disponível em: <https://goo.gl/vzDffC>. Acesso em: 19 fev. 2018.

CUNHA, M. P. The times they are a-changin': a sociedade organizacional à entrada do século XXI. In: ANTONELlO, C. S. et al. Aprendizagem organizacional no Brasil. Porto Alegre: Bookman, 2011. p. XI-XXV. 
DUARTE, J.; MONTEIRO, G. Potencializando a comunicação nas organizações. In: KUNSCH, M. M. K. (Org.). Comunicação organizacional: linguagem, gestão e perspectivas. São Paulo: Saraiva, 2009. p. 333-359. 2 v.

JUCEVICIUS, G. Culture vs. cultures of innovation: conceptual framework and parameters for assessment. In: TSUI, E. (Org.). Proceedings of the 7th International Conference on Intellectual Capital, Knowledge Management \& Organisational Learning. Hong Kong: The Hong Kong Polytechnic University, 2010. p. 236-244.

KAASA, A.; VADI, M. How does culture contribute to innovation? Evidence from European countries. Economics of Innovation and New Technology, [S.1.], v. 19, n. 7, p. 583-604, 2010.

LEONE, N. M. As especificidades das pequenas e médias empresas. Revista de Administração, São Paulo, v. 34, n. 2, p. 91-94, abr./jun. 1999.

MANUCCI, M. El impacto corporativo: diseño estratégico de la comunicación en la complejidad del contexto actual. Buenos Aires: La Crujía, 2008.

MARCHIORI, M. Cultura e comunicação organizacional: um olhar estratégico sobre a organização. 2. ed. São Caetano: Difusão, 2008.

MASSONI, S. Comunicación y sociocultura. Página12, Buenos Aires, 23 enero 2013. La ventana, Medios y Comunicación. Disponível em: <https://goo.gl/BPP8wq>. Acesso em: 19 fev. 2018.

MCLEAN, L. D. Organizational culture's influence on creativity and innovation: a review of the literature and implications for human resource development. Advances in Developing Human Resources, Thousand Oaks, v. 7, n. 2, p. 226-246, 2005.

MESSINA, G. Mudança e inovação educacional: notas para reflexão. Cadernos de Pesquisa, São Paulo, n. 114, nov. 2001. Disponível em: <https://goo.gl/BybV2x>. Acesso em: 19 fev. 2018.

NEVES, J. T. R.; FERREIRA, M. A. T. O apoio à criação de pequenas empresas de base tecnológica: a experiência do Quebec, Canadá. In: SIMPÓSIO DE GESTÃO DA INOVAÇÃO TECNOLÓGICA, 22., 2002, Salvador. Anais... São Paulo: Núcleo de Política e Gestão Tecnológica da USP, 2002.

OLIVEIRA, I. L.; PAULA, M.A. Comunicação estratégica: outras lógicas e construtos no contexto de midiatização. In: CONGRESO DE LA ASOCIACIÓN LATINOAMERICANA DE INVESTIGADORES DE LA COMUNICACIÓN, 12., 2014, Lima. Anais... Lima: PUCP. Disponível em: $<$ https://goo.gl/aBhxin>. Acesso em: 19 fev. 2018.

PUTNAM, L. L.; PHILLIPS, N.; CHAPMAN, P. Metáforas da comunicação e da organização. In: CLEGG, S. R. et al. (Orgs.). Handbook de estudos organizacionais. São Paulo: Atlas, 2012. p. 77-125.

REIS, M. C.; MARCHIORI, M.; CASALI, A. M. A relação comunicação-estratégia no contexto das práticas organizacionais. In: MARCHIORI, M. (Org.). Comunicação e organização: reflexões, processos e práticas. São Caetano do Sul: Difusão, 2010. p. 166-187. 
SERVIÇO BRASILEIRO DE APOIO ÀS MICRO E PEQUENAS EMPRESAS DE SÃO PAULO. 10 anos de monitoramento da sobrevivência e mortalidade de empresas. São Paulo: Sebrae-SP, 2008. Disponível em: <https://goo.gl/5YKYbw>. Acesso em: ago. 2017.

SCHUMPETER, J. A. Teoria do desenvolvimento econômico. São Paulo: Abril Cultural, 1982.

VERAS, T.; SILVA, G. R. A.; PORÉM, M. E. As micro e pequenas empresas nas manchetes do caderno de Economia no Jornal da Cidade de Bauru. In: CONGRESSO BRASILEIRO DE CIÊNCIAS DA COMUNICAÇÃO, 40., 2017, Curitiba. Anais... Curitiba: Universidade Positivo, 2017. p. 1-15. Disponível em <https://goo.gl/YiuAQN>. Acesso em: 19 fev. 2018.

WHitTington, R. O que é estratégia. São Paulo: Pioneira Thomson Learning, 2002.

ZIEN, K. A.; BUCKLER, S. A. From experience dreams to market: crafting a culture of innovation. Journal of Production Innovation Management, [S.1.], v. 14, n. 4, p. 274-287, July 1997. 